\title{
Design and rationale of a randomized control trial testing the effectiveness of combined therapy with STAtin plus FENOfibrate and statin alone in non- diabetic, combined dyslipidemia patients with non-intervened intermediate coronary artery disease - STAFENO study
}

Taek-Geun Kwon ${ }^{1 \dagger}$, Albert Youngwoo Jang ${ }^{2 \dagger}$, Sang Wook Kim³ ${ }^{3}$ Young Joon Hong ${ }^{4}$, Jang-Ho Bae ${ }^{1}$, Sung Yun Lee ${ }^{5}$, Sang-Hyun Kim ${ }^{6}$ and Seung Hwan $\operatorname{Han}^{2^{*}}$

\begin{abstract}
Background: Despite the chronicled success of low-density lipoprotein cholesterol (LDLC)-lowering statin therapy, substantial residual cardiovascular (CV) disease risk remains a problem worldwide, highlighting the need to for combination therapies targeting non-LDLc factors, such as with fenofibrate.

Methods/design: The STAFENO trial is a prospective, randomized, open-label, multi-center trial to compare the effect of statin plus fenofibrate with statin alone on the reduction and stabilization of plaque in non-diabetic, combined dyslipidemia patients with non-intervened, intermediate coronary artery disease (CAD) using virtual histologyintravascular ultrasound at 12 months. A total of 106 eligible patients are planned to be randomized to receive either a combination therapy (rosuvastatin $10 \mathrm{mg}$ plus fenofibrate $160 \mathrm{mg} /$ day) or monotherapy (rosuvastatin $10 \mathrm{mg} /$ day) for 12 months. The primary endpoint of this study is the percentage change in the necrotic core volume. Secondary endpoints include changes in tissue characteristics and 1-year major CV events, including all-cause mortality, CV mortality, nonfatal myocardial infarction, stroke, and revascularization of the intervened and non-intervened lesions. (Continued on next page)
\end{abstract}

\footnotetext{
*Correspondence: shhan@gilhospital.com; kheartist@gmail.com

${ }^{\dagger}$ Taek-Geun Kwon and Albert Youngwoo Jang contributed equally to this work.

2Division of Cardiology, Department of Internal Medicine, Gachon University College of Medicine, Gil Hospital, Incheon, Republic of Korea

Full list of author information is available at the end of the article
}

(c) The Author(s). 2020 Open Access This article is licensed under a Creative Commons Attribution 4.0 International License, which permits use, sharing, adaptation, distribution and reproduction in any medium or format, as long as you give appropriate credit to the original author(s) and the source, provide a link to the Creative Commons licence, and indicate if changes were made. The images or other third party material in this article are included in the article's Creative Commons licence, unless indicated otherwise in a credit line to the material. If material is not included in the article's Creative Commons licence and your intended use is not permitted by statutory regulation or exceeds the permitted use, you will need to obtain permission directly from the copyright holder. To view a copy of this licence, visit http://creativecommons.org/licenses/by/4.0/ The Creative Commons Public Domain Dedication waiver (http://creativecommons.org/publicdomain/zero/1.0/) applies to the data made available in this article, unless otherwise stated in a credit line to the data. 
(Continued from previous page)

Discussion: The STAFENO trial will address whether combination treatment of statin and fenofibrate has an additive beneficial effect compared to statin alone on the reduction and stabilization of plaque and CV events in non-diabetic, combined dyslipidemia patients with non-intervened intermediate CAD.

Trial registration: ClinicalTrials.gov, NCT02232360. Registered 9 February 2014. https://register.clinicaltrials.gov/prs/app/action/SelectProtocol?sid=S0004ULE\&selectaction=Edit\&uid=U00023SZ\&ts= $2 \& c x=j u p p d 2$

Keywords: Residual cardiovascular risk, Statin, Fenofibrate, Combination therapy, Virtual histology intravascular ultrasound, Randomized control trial

\section{Background}

Coronary artery disease (CAD) is the leading cause of cardiovascular (CV) disease in developed countries, with approximately 1,350,000 patients presenting with acute coronary syndrome (ACS) annually in the United States alone [1]. Although percutaneous coronary intervention and optimal low-density lipoprotein cholesterol (LDLc)lowering statin therapy have substantially reduced recurrent CV events in ACS, two-thirds of the CV disease risk remains [2-7]; this highlights the need to redirect the current $\mathrm{CV}$ reduction algorithms to focus beyond LDLc reduction and the use of statins $[7,8]$.

In the 2016 European guidelines for the management of dyslipidemias [9], non-high density lipoprotein cholesterol (non-HDLc) is indicated as a strong independent risk factor and should be a a secondary treatment target (class IIa, level of evidence B). In these guidelines, in high-risk patients with triglyceride (TG) more than 200 $\mathrm{mg} / \mathrm{dL}$ despite statin treatment, fenofibrate may be considered for use in combination with statins (class IIa, level of evidence B). Although the FIELD and ACCORD trials did not demonstrate favorable efficacy of fenofibrate in diabetic patients, these studies showed that fenofibrate treatment reduced the $\mathrm{CV}$ event rate in patients with high TG or low HDLc levels [10, 11]. A meta-analysis of fibrates on $\mathrm{CV}$ outcomes also confirmed a significant reduction in $\mathrm{CV}$ disease risk without an increase in drug-related adverse events [12]. These data suggest that statin and fenofibrate combination therapy is a potential alternative to statin alone in CAD patients with high levels of non-HDLc. Angiographically, mild atherosclerotic plaques account for $50 \%$ of recurrent $\mathrm{CV}$ events, further bringing non-culprit vessels into focus as a useful surrogate marker for future CV events [5]. Virtual histology (VH)-intravascular ultrasound (IVUS) allows the tissue characterization and quantitative assessment of plaque, which provides an extensive understanding of the non-culprit lesions [13]. Here, we seek to determine the additive impact of fenofibrate versus optimal statin therapy on non-culprit lesions in non-diabetic, combined dyslipidemia patients with non-intervened intermediate coronary artery disease using well-defined VH-IVUS criteria.

\section{Methods/design}

\section{Study design and subjects}

This is a prospective, open-label, randomized, multicenter trial to investigate the efficacy of statin plus fenofibrate treatment compared to treatment with statin alone in non-diabetic, combined dyslipidemia patients with non-intervened intermediate CAD.

A brief flowchart of the study is summarized in Fig. 1.

In non-diabetic patients with suspected CAD, coronary angiography (CAG) will be performed with the standard technique. Percutaneous coronary intervention (PCI) will be performed in culprit lesions based on the decision of an interventionist in participating centers within Korea [14]. Non-culprit lesions (index lesions) with intermediate stenosis (percentage diameter stenosis, 30-60\%) by CAG will be evaluated by VH-IVUS if the patients meet the study inclusion and exclusion criteria. Data will be stored for off-line analysis.

Patients will be randomized at ratio of 1:1 using a random table (made by matches of age, sex, presentation of coronary artery disease and sequentially numbered) to receive either rosuvastatin $10 \mathrm{mg}$ plus fenofibrate $160 \mathrm{mg}$ or rosuvastatin $10 \mathrm{mg}$ alone. Study drugs will be administered after the index VH-IVUS. Biochemical laboratory tests (fasting state) will be performed at the time of CAG and followed up at the third month ( \pm 2 months) and 12th month ( \pm 2 months). Follow-up CAG and VHIVUS examination will be performed at the 12th month ( \pm 2 months). Clinical events will be followed up by office visit or by telephone contact if necessary. Adherence to the study drugs will be checked at every outpatient visit, and the decision to discontinue any of the study drugs will be discussed and checked under the recommendation of the responsible cardiologist. Other drugs which influence lipid profiles will be prohibited during the trial period.

\section{Study objectives and hypotheses}

The primary objective of this study is to compare the changes in percentage necrotic core volume (NCV) and absolute NCV in non-culprit intermediate lesions in non-diabetic, combined dyslipidemia patients after 12 


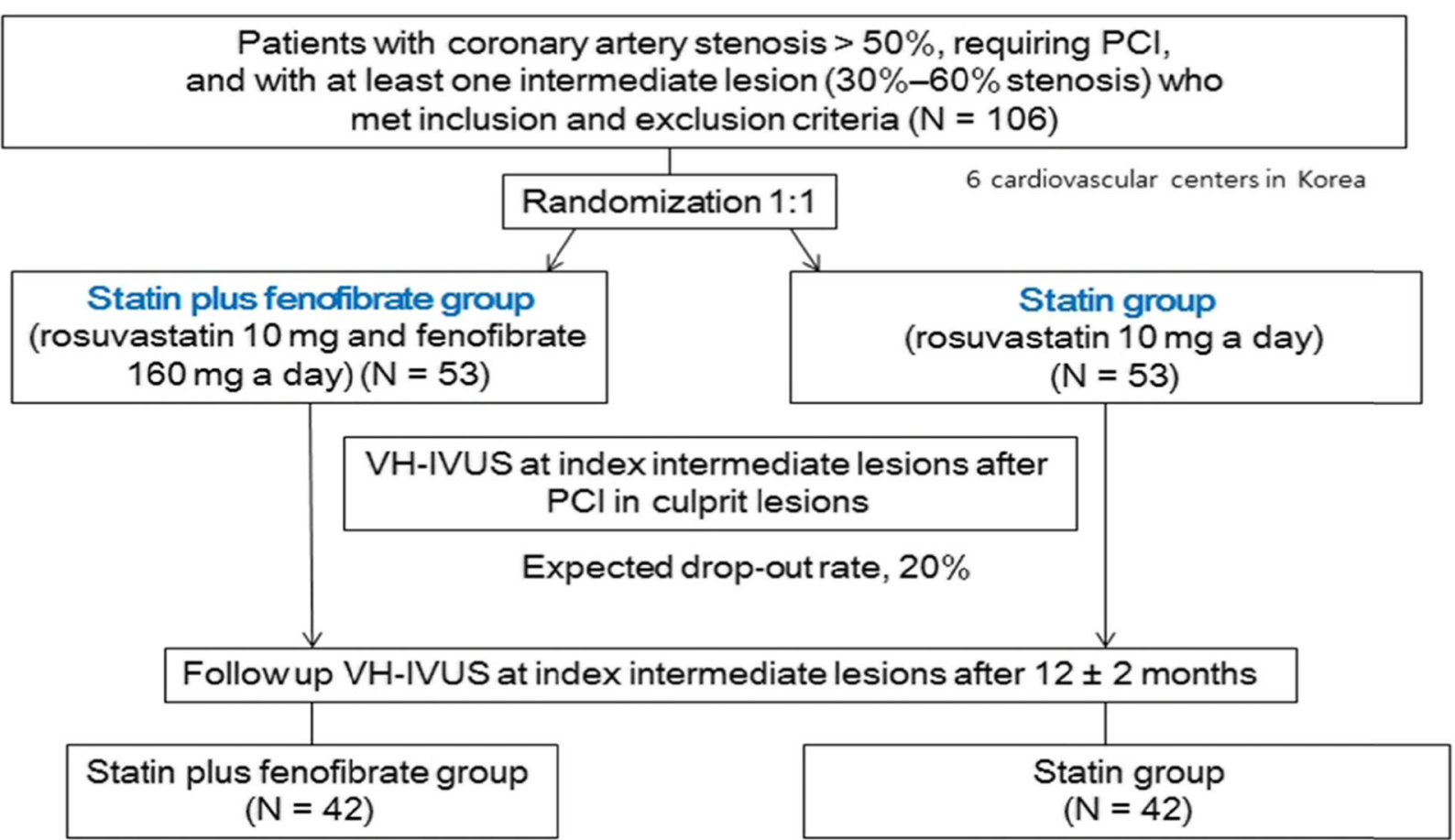

\section{Primary endpoint:}

$\%$ and absolute change of NC volume after $12 \pm 2$ months

Secondary endpoints:

Composition and phenotype change of plaque

MACE

Changes of lipids, inflammatory marker (CRP), and adiponectin, and their relationship

with plaque changes

Fig. 1 A Brief Flowchart of the Study

months' therapy with statin plus fenofibrate compared to statin alone. The working hypothesis of this trial is that statin plus fenofibrate combination therapy is superior to statin alone therapy in reducing the 12-month percentage NCV and the absolute NCV. The secondary objective is to compare changes in percentage and absolute dense calcium (DC), fibrofatty (FF) and fibrous (F) plaques, the incidence of and changes in thin cap fibroatheroma (TCFA), the changes in variables of grey scale IVUS (volumes of external elastic membrane, lumen, and plaque), and the remodeling index between the statin plus fenofibrate and statin alone groups. In addition, secondary endpoints will include comparisons of major adverse cardiac events (MACEs) at 12 months, defined as all-cause death, CV death, nonfatal myocardial infarction (MI), stroke, and ischemia-driven revascularization of intervened and non-intervened lesions between the two groups. In order to identify the mechanisms of plaque stability and regression, the relationships between the variables of the VH-IVUS parameters and laboratory markers, including lipids, inflammatory markers, and metabolic markers, in the statin plus fenofibrate and statin alone groups will be investigated. The incidence of drug adverse effects will be another secondary endpoint of the study.

\section{Study organization}

A total of six CV centers in Korea will participate in this trial; these centers include Gachon University Gil Hospital, Chung-Ang University Hospital, Chonnam National University Hospital, Konyang University Hospital, Seoul National University Borame Hospital, and Inje University Ilsan Paik Hospital. The protocol of the trial is registered at http://clnicaltrials.gov (NCT02232360).

This study is an investigator-initiated study sponsored by Dae-woong pharmaceutical company (Seoul, Korea, $+82,025,508,800)$. The authors alone are responsible for the design and execution of the trial, related statistical analyses, all aspects of the manuscript preparation, including the drafting, editing, and final content, data 
monitoring, and reporting of adverse events to the institutional review board (IRB) of each participating center.

\section{Study population and entry criteria}

Inclusion criteria are as follows: (1) age $\geq 20$ years; (2) presence of non-culprit intermediate lesions confirmed by index CAG; and (3) combined dyslipidemia (baseline LDLc $\geq 70 \mathrm{mg} / \mathrm{dL}$ and non-HDLc $\geq 130 \mathrm{mg} / \mathrm{dL}$ in statin-naïve patients, and baseline LDLc $\leq 100 \mathrm{mg} / \mathrm{dL}$ and non-HDLc $\geq 100 \mathrm{mg} / \mathrm{dL}$ in patients on statin treatment). A non-culprit lesion is defined as a VH-IVUSfeasible native coronary lesion with $30-60 \%$ stenosis, $2.0-4.0 \mathrm{~mm}$ in diameter by visual estimation during CAG, and located more than $10 \mathrm{~mm}$ apart from the intervened lesion.

Exclusion criteria are as follows: (1) diabetic patients; (2) poor cardiac, renal, or hepatic function; (3) explicit side effects and/or contraindications to lipid-lowering agents, including pregnancy, breastfeeding, and familial hypercholesterolemia; (4) very high triglyceridemia (TG $\geq 500 \mathrm{mg} / \mathrm{dL}$ ); (5) lesions that might cause difficulties for VH-IVUS. Detailed inclusion and exclusion criteria are summarized in Table 1.

\section{Randomization, interventions, and data assessment}

The schedule of enrolment, interventions, and assessments is outlined in Fig. 2.

Written informed consent for subjects who meet clinical and angiographic inclusion and exclusion criteria will be obtained by an investigator. Personal information is planned to be corrected by interview and chart review. All personal information will be protected by an encoding process. Potential participants are informed of the purpose of the study, the potential hazards and risks, the potential benefits, the procedure, and the expected follow-up after intervention. They are informed that participation is voluntary and that withdrawal from the study may occur at any time. On the consent form, participants will be asked if they agree to the use of their data should they choose to withdraw from the trial. Participants will also be asked for permission for the research team to share relevant data with people from the universities taking part in the research or from regulatory authorities, where relevant. This trial involves collecting biological specimens for storage. Additional permission for storage and measurement of biological specimens will be acquired from participants according to the local IRB's requests.

After the subjects are enrolled in the present study, subjects will be randomized to two groups using a random box table made by stratified randomization according to subjects' age, sex, and clinical presentation (acute coronary syndrome or not).
Table 1 Inclusion and exclusion criteria

\section{Inclusion criteria}

- Patients with coronary artery disease who were 20 years of age or older and required coronary angiography

- Patients who require $\mathrm{PCl}$ in culprit lesions

- Intermediate coronary artery stenosis (diameter stenosis $\geq 30 \%$ to $\leq$ $60 \%$ by visual estimation, diameter $\geq 2.0 \mathrm{~mm}$ to $\leq 4.0 \mathrm{~mm}$, de novo lesion in native coronary artery, more than $10 \mathrm{~mm}$ distance from $\mathrm{PCl}$ sites) in which virtual histology-intravascular ultrasound (VH-IVUS) is feasible

- Statin naïve subjects: Combined dyslipidemia (LDLc $\geq 70 \mathrm{mg} / \mathrm{dL}$ and non-HDLc $\geq 130 \mathrm{mg} / \mathrm{dL}$ )

- In statin subjects: LDLc $\leq 100 \mathrm{mg}$ and non-HDLc $\geq 100 \mathrm{mg} / \mathrm{dL}$

- Patients who provided written informed consent

\section{Exclusion criteria}

- Diabetic patients

- Patients with a history of the use of other lipid-modifying agents (except statins) within the 2 weeks prior to the trial beginning

- Cardiogenic shock

- Heart failure with symptoms of New York Heart Association class III/IV or a left ventricular ejection fraction $<35 \%$

- Renal dysfunction (creatinine level $\geq 1.7 \mathrm{mg} / \mathrm{dL}$ ) or dependence of dialysis

- Hepatic dysfunction (transaminase level more than three times that of the normal limit)

- Pregnancy or breastfeeding women or women of childbearing age

- Familial hypercholesterolemia

- Hypertriglyceridemia (triglyceride level > $500 \mathrm{mg} / \mathrm{dL}$ )

- Lesions that might cause difficulties for VH-IVUS due to the following reasons: heavy calcification ( $>90^{\circ}$ arc), tortuous vessel with severe angulation, total occlusion, or major bifurcation lesions (side branch diameter $>2 \mathrm{~mm}$ )

- Inability to take adequate antiplatelet therapy (aspirin, clopidogrel, ticagrelor, or prasugrel)

- Thrombocytopenia (platelet count $<70 \times 10^{9} / \mathrm{L}$ )

- History of significant arrhythmia including ventricular tachyarrhythmia - Familial hypercholesterolemia

\section{Research materials}

\section{VH-IVUS and quantitative coronary angiography}

VH-IVUS using a synthetic-aperture-array, 20-MHz, 3.2French catheter (Eagle Eye, In-Vision gold, Volcano Corp, rancho Cordova, CA, USA) with motorized catheter pullback ( $0.5 \mathrm{~mm}$ per second) after intracoronary administration of nitroglycerin $0.2 \mathrm{mg}$ will be performed in non-culprit lesions with intermediate stenosis. During pullback, grayscale IVUS is recorded and raw radiofrequency data are captured at the top of the $\mathrm{R}$ wave for the reconstruction of the colorcoded map by a VH-IVUS data recorder (Volcano Therapeutics). Enrolled lesions will be native vessels and should be located more than $10 \mathrm{~mm}$ apart from the intervened lesion. Cases where the patients' condition is unstable or the characteristics of the lesions make it difficult 


\begin{tabular}{|c|c|c|c|c|c|c|}
\hline \multirow[b]{2}{*}{ TIMEPOINT** } & \multirow{2}{*}{$\begin{array}{c}\text { Enrolment } \\
\begin{array}{c}\text { Baseline } \\
\text { Visit1 }\end{array}\end{array}$} & \multirow{2}{*}{$\begin{array}{c}\text { Randomization } \\
\begin{array}{c}\text { Baseline } \\
\text { Visit } 1\end{array}\end{array}$} & \multicolumn{3}{|c|}{ Post-randomization } & \multirow{2}{*}{$\begin{array}{c}\text { Close-out } \\
12 M( \pm) \\
2 M \\
\text { Visit } 5 \\
\end{array}$} \\
\hline & & & $\begin{array}{c}M( \pm) \\
2 M \\
\text { Visit } 2 \\
\end{array}$ & $\begin{array}{c}6 M( \pm) \\
2 M \\
\text { Visit } 3 \\
\end{array}$ & $\begin{array}{c}9 M( \pm) \\
2 M \\
\text { Visit 43 } \\
\end{array}$ & \\
\hline \multicolumn{7}{|l|}{ ENROLLMENT } \\
\hline Medical/clinical history & & & & & & \\
\hline & $\mathrm{X}$ & $\mathrm{x}$ & & & & $\mathrm{X}$ \\
\hline Demography/medical history & $\mathrm{X}$ & & & & & \\
\hline Inclusion/exclusion criteria & $\mathrm{X}$ & & & & & \\
\hline Informed consent & $\mathrm{X}$ & & & & & \\
\hline Randomization for therapy & & $\mathrm{x}$ & & & & \\
\hline \multicolumn{7}{|l|}{ INTERVENTIONS } \\
\hline \multicolumn{7}{|l|}{$\begin{array}{l}\text { Rosuvastatin } 10 \mathrm{mg} \text { plus } \\
\text { fenofibrate } 160 \mathrm{mg}\end{array}$} \\
\hline \multicolumn{7}{|l|}{ Rosuvastatin $10 \mathrm{mg}$} \\
\hline \multicolumn{7}{|l|}{ Outcome variables } \\
\hline Biochemistry laboratories & & $\mathrm{X}$ & $\mathrm{X}$ & & & $\mathrm{X}$ \\
\hline Sampling of plasma & & $\mathrm{X}$ & & & & $\mathrm{X}$ \\
\hline Coronary angiogram & & $\mathrm{X}$ & & & & $\mathrm{X}$ \\
\hline VH-IVUS & & $\mathrm{X}$ & & & & $\mathrm{X}$ \\
\hline \multicolumn{7}{|l|}{ Other data variables } \\
\hline Drug compliance & & & $\mathrm{X}$ & $\mathrm{X}$ & $\mathrm{X}$ & $\mathrm{X}$ \\
\hline Adverse events & & & $\mathrm{X}$ & $\mathrm{X}$ & $\mathrm{x}$ & $\mathrm{X}$ \\
\hline 12-lead ECG & & $\mathrm{X}$ & $X$ & & & $\mathrm{X}$ \\
\hline
\end{tabular}

Fig. 2 Schedule of enrolment, interventions, and assessments

to perform VH-IVUS in terms of severe angulated lesions, calcified lesions, or thrombus containing lesions, will be excluded.

Data from the VH-IVUS and CAG will be measured by an independent investigator who is blinded to patient group and characteristics. Data from VH-IVUS, such as percentage and absolute NCV, DC volume, F volume, FF volume, and presence of thin cap fibroatheroma (TCFA), and data for the gray IVUS, such as external elastic membrane, lumen, plaque volume, and the remodeling index, will be measured in the entire index segment and the most severe $10 \mathrm{~mm}$ segment centered on the minimal lumen area at baseline and after 12 months.

Data from CAG, such as reference vessel diameter, minimal lumen diameter, and lesion lengths, will be measured by a dedicated quantitative coronary angiography (QCA) program.

\section{Laboratory assessment}

Lipid profiles (total cholesterol, HDLc, TG, apolipoprotein A-1, and apolipoprotein-B), hs CRP, metabolic markers (fasting blood sugar and hemoglobin A1c), renal and hepatic function, and creatine phosphokinase (CPK) will be measured at baseline and after 12 months. At both baseline and after 12 months, sampled blood will be collected in ethylenediamine tetraacetic acid (EDTA) bottles, centrifuged for $15 \mathrm{~min}$ at $1000 \mathrm{~g}$, and stored in a freezer at temperatures below $-70{ }^{\circ} \mathrm{C}$. Using stored plasma, the levels of adiponectin, lipoprotein-associated phospholipase A2, and 
fatty acid binding protein will be measured at the end of the study using specific ELISA kits.

\section{Study endpoints}

The primary endpoint of this study is the comparison of the change in percentage NCV and absolute NCV between statin plus fenofibrate and statin alone groups of non-diabetic, combined dyslipidemia patients with nonintervened intermediate coronary artery disease at 12 months. The secondary endpoints are as follows: 1) comparisons of the changes in other tissue components of percentage and absolute plaque volume in index nonintervened lesions, including DC, FF, and F; 2) change in plaque phenotypes such as TCFA; 3) change in grey IVUS parameters, including vessel area/volume, lumen area/volume, plaque area/volume, and remodeling index; 4) MACEs for 12 months, including all cause death, CV death, nonfatal myocardial infarction, stroke, and ischemia-driven revascularization of intervened and non-intervened lesions; 5) relationships between the changes in tissue components of plaque and changes in laboratory findings; 6) adverse reactions to the study drugs, including myalgia, elevation of CPK more than twice the upper limit of normal, and hepatic dysfunction (alanine aminotransferase more than three times the upper limit of normal).

\section{Participant follow-up}

Clinical follow-up will take place at 3,6, and 9 months and 1 year by clinical visit or telephone interview if needed. Laboratory follow-up will take place at 3 months (not obligatory) and 1 year. Follow up CAG and VHIVUS will take place 12 months after randomization. At all planned contacts during the treatment period, patients will be asked whether they have adhered to the correct drug administration. Subjects with trial-related adverse events during the study period will be compensated for the standard of care by LIG Insurance Co., Ltd (Seoul, Korea).

\section{Statistical considerations}

\section{Sample size calculations}

Based on a previous study [15], a sample size of approximately 42 patients per treatment group was calculated to provide $80 \%$ power (assuming a standard deviation of 7.82 ) to detect a difference of 4.78 in percentage NCV and to detect the superiority of statin plus fenofibrate compared to statin alone with a two-sided alpha level of 0.05 . With a statin plus fenofibrate:satin alone sampling ratio of $1: 1$ and a dropout rate of $20 \%$, a final sample size of 53 patients per treatment group (total 106 patients) was specified in order to provide an adequate number of evaluable patients. To the best of the researchers' knowledge, no study has been conducted on the change of tissue characteristics after fenofibrate treatment. We hypothesized that fenofibrate has an effect on percentage NCV as much as that of $10 \mathrm{mg}$ atorvastatin [15]. In addition, a previous study [16] consisting of 100 patients with non-significant lesions demonstrated a significant decrease in NCV in the rosuvastatin $(10 \mathrm{mg} /$ day $)$ treated group but not in the simvastatin treated group $(20 \mathrm{mg} /$ day $)$.

\section{Statistical analyses}

The primary endpoint of percentage NCV and absolute NCV will be analyzed using a paired-sample $t$-test or Wilcoxon rank-sum test for changes within each group, and an unpaired $t$-test or Mann-Whitney $\mathrm{U}$ test for differences between the two groups. Continuous variables will be expressed as mean \pm standard deviation and compared by either a Student's $t$-test or Mann-Whitney U test based on whether or not the data are normally distributed. Categorical variables will be expressed as number or percentage and compared by $\chi^{2}$ or Fisher's exact test. Pearson correlation test will be used to evaluate the correlation between the changes in percentage NCV and absolute NCV, and changes in laboratory findings from baseline to follow-up. These statistical analyses will be performed in the entire index non-culprit segment and the most severe $10-\mathrm{mm}$ segment centered on the minimal lumen area.

Multivariable linear regression analysis will be performed in order to identify the independent predictors of the reduction in percentage NCV. To analyze the secondary endpoints, VH-IVUS parameters, grey IVUS parameters, and angiographic parameters will be analyzed using a paired sample $t$-test or Wilcoxon rank-sum test for changes within each group, and an unpaired $t$-test or Mann-Whitney $U$ test for differences between the two groups. Correlations between these parameters and laboratory variables will be evaluated by the Pearson correlation test.

Changes in the phenotypes of the index lesions between the two groups will be compared by $x^{2}$ or Fisher's exact test. The composite endpoint of CV events will be analyzed by comparing the Kaplan-Meier event rates using a log-rank test. A $p$ value $<0.05$ will be considered statistically significant.

\section{Trial organization}

\section{Executive Committee}

The Executive Committee will be composed of the study principal investigator and the sub-principal investigator of each participating center. This committee will approve important protocol modifications and the final trial design. Protocol modifications will be issued to the Data Safety Monitoring Board (DSMB) after communicating with local IRBs. The Executive Committee will also be responsible for the final results and determining the methods of presentation and publication. 


\section{Endpoint Adjudication Committee}

The Endpoint Adjudication Committee (EAC) comprises interventional and non-interventional cardiologists who do not participate in the study. This will be in charge of the development of specific criteria of endpoints based on study protocol and will review the accuracy and adequacy of reported endpoints.

\section{Data Safety Monitoring Board}

The DSMB is composed of general and interventional cardiologists. The DSMB policies will be in accordance with relevant regulatory guidelines. The board members will be independent of the trial. The safety data from the current study will be reviewed by the DSMB committee. Recommendations will be made based on safety analyses of unanticipated serious adverse events and protocol deviation. The DSMB will be provided with all cumulative safety data throughout enrollment and follow-up periods to ensure patient safety. All DSMB reports will be confidential, but will be available to relevant agencies upon request.

\section{Ethics approval and auditing}

The study is performed according to the principles of the Declaration of Helsinki and the common guidelines for clinical trials (ICH-GCP). This study has been approved by the IRB of Gachon University Gil Hospital and each participating center. Auditing will be carried out by the IRB of each participating center for adequacy of subjects enrollment, intervention, and data monitoring.

\section{Discussion}

The STAFENO trial will determine the efficacy of fenofibrate in the reduction and stabilization of plaque in index non-culprit intermediate lesions with background treatment of statin in non-diabetic patients with mixed dyslipidemia. In addition, plausible mechanisms of plaque changes will be investigated through the direct relationships with changes in lipids, inflammatory markers, and metabolic markers. The STAFENO trial will provide insights into the combined treatment with statin and fenofibrate in non-diabetic, intermediate CAD patients with combined dyslipidemia.

\section{Rationale behind selecting fenofibrate for residual risk reduction}

Despite the chronicled success of LDLc-lowering statin therapy, residual $\mathrm{CV}$ disease risk remains a worldwide burden, highlighting the need for targets other than LDLc, such as niacin and fibrates $[7,8,17]$. Furthermore, the prevalence of hypertriglyceridemia is greater than hypercholesterolemia within the Korean population [18-20], in the Chinese National Survey [21], and in Japanese men (http://www.mhlw.go.jp/bunya/kenkou/eiyou/h25- houkoku.html). In addition, a 2007 Korean National Survey revealed that $33.2 \%$ of the general population had hypertriglyceridemia (triglycerides $\geq 150 \mathrm{mg} / \mathrm{dL}$ ), and that $50.2 \%$ of them had low HDLc levels (men $<40 \mathrm{mg} / \mathrm{dL}$, women $<50 \mathrm{mg} / \mathrm{dL}$ ) [22]. It is important to mention that recent genetic studies and randomized trials demonstrated that low HDLc might not be a cause of CV disease; instead, the risk of $\mathrm{CV}$ disease may be exacerbated by hypertriglyceridemia and remnant cholesterol [7, 23]. Therefore, the treatment of combined dyslipidemia is very important in reducing remnant $\mathrm{CV}$ disease risk, especially in the Asian population [7]. However, for the treatment of combined dyslipidemia, in terms of high LDLc and hypertriglyceridemia, or high non-HDLc, niacin plus statin combination therapy was associated with an increased risk of adverse effects, such as new-onset diabetes mellitus, diabetic complications, gastrointestinal problems, bleeding, and infection, and a lack of improvement in clinical outcomes, thereby limiting its use [24, 25].

Fibric acid, a synthetic ligand of the peroxisome proliferator-activated receptor (PPAR) $\alpha$, is an effective drug for lowering plasma TG and increasing HDLc $[8,26]$. In addition, PPAR $\alpha$ activation by fenofibrate improves insulin sensitivity and endothelial function and decreases thrombosis and vascular inflammation [27, 28]. In ApoE*3 leiden mice fed a high cholesterol diet, fenofibrate reduces atherosclerosis more than can be explained by the lowered total plasma cholesterol. The anti-atherogenic effects of fenofibrate might be responsible for the regression of coronary plaque [29] and reducing the coronary events associated with atherosclerosis. Furthermore, impaired recruitment of monocytes/macrophages, reduced vascular and systemic inflammation, and stimulation of cholesterol efflux may all contribute to these beneficial effects of fenofibrate [30].

Our group has previously shown that in humans PPAR $\alpha$ activation by fenofibrate has additive beneficial effects, improving insulin sensitivity and endothelial function, while decreasing thrombosis and vascular inflammation compared to treatment with statin alone [27, 28]. Although the FIELD and ACCORD trials in diabetic patients did not demonstrate a significant reduction in the primary composite outcome of the addition of fenofibrate, post hoc analysis has shown that the use of fenofibrate in patients with elevated TG or low HDLc levels was associated with a reduction in CV disease risk [11, 31]. In addition, a meta-analysis of the effect of fibrates demonstrated a $10 \%$ relative risk reduction for MACE and a 13\% relative risk reduction for coronary events without a significant increase in serious drug-related adverse events [12]. Although an increased incidence of myopathy was associated with the use of statin plus gemfibrozil, it was not with statin plus fenofibrate therapy [32]. After reviewing our previous findings and the literature, we concluded that fenofibrate plus statin may be an excellent candidate for conferring additive beneficial 
effects on reduction of residual $\mathrm{CV}$ disease risk compared to statin alone therapy. In this study, we will enroll combined dyslipidemia patients (baseline LDLc $\geq 70 \mathrm{mg} / \mathrm{dL}$ and non-HDLc $\geq 130 \mathrm{mg} / \mathrm{dL}$ in statin-naïve patients, and baseline LDLc $\leq 100 \mathrm{mg} / \mathrm{dL}$ and non-HDLc $\geq 100 \mathrm{mg} / \mathrm{dL}$ in patients with statin treatment) in order to test our hypothesis.

\section{The rationale for VH-IVUS-measured percentage $\mathrm{NCV}$ as a primary endpoint}

The PROSPECT trial revealed that non-culprit lesions account for a substantial proportion of future CV events [5]. Independent predictors for future $\mathrm{CV}$ events were a plaque burden $\geq 70 \%$, VH-IVUS-proven TCFA, and a minimum lumen area $\leq 4.0 \mathrm{~mm}^{2}$. Similarly, the VIVA study revealed that such predictors were related to a high degree of angiographic diameter stenosis, which may explain why subsequent clinical events were linked to baseline non-culprit lesion severity [33]. As these data prove VH-IVUS as a legitimate in vivo diagnostic modality for delineating the relationship between non-culprit lesions and CV events, we decided to use VH-IVUS to track the quantitative change in $\mathrm{NC}$ and the characteristic change in TCFA in both treatment arms.

\section{Intermediate statin dosage}

The incremental benefits associated with higher doses of statins has led to the guidelines recommending the use of high doses of statins in patients with high CV disease risk $[2-4,6,34]$. However, in Asian patients, for the regression of coronary atherosclerotic plaques and reducing MACEs, an intermediate dose of rosuvastatin (10 $\mathrm{mg}$ /day) is as effective as high-intensity statins with minimal adverse reactions $[35,36]$. The administration of rosuvastatin $(10 \mathrm{mg})$ in the STAFENO trial was based on this rationale.

\section{Study limitations}

The possible limitations of the STAFENO trial are the relatively small study population, although the sample size was calculated based on previous IVUS study, and the relatively short term follow-up.

Therefore, if statin plus fenofibrate shows more beneficial results in terms of changes in plaque volume and characteristics, it will provide the rationale for largescale randomized clinical trials to demonstrate the efficacy of combined treatment of statin and fenofibrate in non-diabetic CAD patients with combined dyslipidemia.

\section{Conclusions}

We believe that the STAFENO trial will address whether combination statin plus fenofibrate treatment has additive beneficial effects compared to statin alone on the reduction and stabilization of $\mathrm{NCV}$, and the plausible mechanisms of these results, in non-culprit plaques of non-diabetic patients with combined dyslipidemia.

\section{Trial status}

Patient recruitment is ongoing (102/106 subjects, 96.2\%) and the completion of the study is estimated to be in December 2020. The latest protocol is version 1.9, last updated on December 17th, 2018.

\section{Abbreviations \\ ACS: Acute coronary syndrome; CAD: Coronary artery disease; CAG: Coronary angiography; CV: Cardiovascular; DC: Dense calcium; FF: Fibrofatty; F: Fibrous; HDLc: High-density lipoprotein cholesterol; LDLc: Low-density lipoprotein cholesterol; MACE: Major adverse cardiac event; NCV: Necrotic core volume; PPAR: Peroxisome proliferator-activated receptor; TCFA: Thin cap fibroatheroma; TG: Triglycerides; QCA: Quantitative coronary angiography; VH-IVUS: Virtual histology-intravascular ultrasound}

\section{Authors' contributions}

All authors participated in the conception and design of the study. Kwon TG and Jang AY contributed equally to the preparation of this manuscript. Bae $J$ H, Kim SW, Hong YJ, Lee SY, Kim SH, and Han SH will enroll patients and collect clinical and IVUS data. Han SH and Jang AY will analyze laboratory assessments. Kim SW will analyze IVUS and VH images in the core lab. The principal investigator, Han $\mathrm{SH}$, initiated the study, obtained funding, designed the study, and supervised the writing of the manuscript. All authors read and approved the final manuscript.

\section{Funding}

This is an investigator-initiated clinical trial with grant support from Daewoong Pharmaceutical Co. Ltd (Seoul, Korea). The sponsor has no role in the development of study protocols or study processes, including site selection, management, and data collection and analysis. The authors are solely responsible for the design and editing of this paper and its final content.

Availability of data and materials

The datasets of the current study will be available by the corresponding author upon reasonable request.

Ethics approval and consent to participate

The study protocol and other associated documents have been approved by the IRB of Gachon University Gil Medical Center and other local IRBs of participating centers. The principal investigators or sub-principal investigators will be responsible for obtaining written informed consent from patients before enrollment. The informed consent form is available from the corresponding author on request.

Consent for publication

Not applicable.

\section{Competing interests}

All authors declare that they have no competing interests from Dae-woong Pharmaceutical Co. Ltd (Seoul, South Korea) or other partners.

\section{Author details}

${ }^{1}$ Division of Cardiology, Department of Internal Medicine, College of Medicine, Konyang University Hospital, Daejeon, Republic of Korea. ${ }^{2}$ Division of Cardiology, Department of Internal Medicine, Gachon University College of Medicine, Gil Hospital, Incheon, Republic of Korea. ${ }^{3}$ Division of Cardiology, Department of Internal Medicine, Cardiovascular-Arrhythmia Center, Chung-Ang University Hospital, Seoul, Republic of Korea. ${ }^{4}$ Division of Cardiology, Department of Internal Medicine, Chonnam National University Hospital, Gwangju, Republic of Korea. ${ }^{5}$ Division of Cardiology, Department of Internal Medicine, Inje University Ilsan Paik Hospital, Goyang, Republic of Korea. ${ }^{6}$ Division of Cardiology, Department of Internal Medicine, Cardiovascular Center, Seoul National University College of Medicine Boramae Medical Center, Seoul, Republic of Korea. 
Received: 25 October 2019 Accepted: 28 March 2020 Published online: 22 April 2020

\section{References}

1. Benjamin EJ, Virani SS, Callaway CW, Chamberlain AM, Chang AR, Cheng S, Chiuve SE, Cushman M, Delling FN, Deo R, de Ferranti SD, Ferguson JF, Fornage M, Gillespie C, Isasi CR, Jimenez MC, Jordan LC, Judd SE, Lackland D, Lichtman JH, Lisabeth L, Liu S, Longenecker CT, Lutsey PL, Mackey JS, Matchar DB, Matsushita K, Mussolino ME, Nasir K, O'Flaherty M, Palaniappan LP, Pandey A, Pandey DK, Reeves MJ, Ritchey MD, Rodriguez CJ, Roth GA, Rosamond WD, UKA S, Satou GM, Shah SH, Spartano NL, Tirschwell DL, Tsao CW, Voeks JH, Willey JZ, Wilkins JT, Wu JH, Alger HM, Wong SS, Muntner P. Heart disease and stroke statistics-2018 update: a report from the American Heart Association. Circulation. 2018;137:e67-e492.

2. Cannon CP, Braunwald E, McCabe CH, Rader DJ, Rouleau JL, Belder R, Joyal SV, Hill KA, Pfeffer MA, Skene AM, Pravastatin or Atorvastatin E, Infection Therapy-Thrombolysis in Myocardial Infarction I. Intensive versus moderate lipid lowering with statins after acute coronary syndromes. N Engl J Med. 2004;350:1495-504.

3. LaRosa JC, Grundy SM, Waters DD, Shear C, Barter P, Fruchart JC, Gotto AM, Greten H, Kastelein JJ, Shepherd J, Wenger NK, Treating to New Targets I. Intensive lipid lowering with atorvastatin in patients with stable coronary disease. N Engl J Med. 2005;352:1425-35.

4. Pedersen TR, Faergeman O, Kastelein JJ, Olsson AG, Tikkanen MJ, Holme I, Larsen ML, Bendiksen FS, Lindahl C, Szarek M, Tsai J, Incremental Decrease in End Points Through Aggressive Lipid Lowering Study G. High-dose atorvastatin vs usual-dose simvastatin for secondary prevention after myocardial infarction: the IDEAL study: a randomized controlled trial. JAMA. 2005;294:2437-45.

5. Stone GW, Maehara A, Lansky AJ, de Bruyne B, Cristea E, Mintz GS, Mehran R, McPherson J, Farhat N, Marso SP, Parise H, Templin B, White R, Zhang Z, Serruys PW, Investigators P. A prospective natural-history study of coronary atherosclerosis. N Engl J Med. 2011;364:226-35.

6. Stone NJ, Robinson JG, Lichtenstein AH, Bairey Merz CN, Blum CB, Eckel RH, Goldberg AC, Gordon D, Levy D, Lloyd-Jones DM, McBride P, Schwartz JS, Shero ST, Smith SC Jr, Watson K, Wilson PW, American College of Cardiology/American Heart Association Task Force on Practice G. 2013 ACC/ AHA guideline on the treatment of blood cholesterol to reduce atherosclerotic cardiovascular risk in adults: a report of the American College of Cardiology/American Heart Association Task Force on Practice Guidelines. J Am Coll Cardiol. 2014;63:2889-934.

7. Han SH, Nicholls SJ, Sakuma I, Zhao D, Koh KK. Hypertriglyceridemia and cardiovascular diseases: revisited. Korean Circ J. 2016;46:135-44.

8. Han SH, Quon MJ, Koh KK. Beneficial vascular and metabolic effects of peroxisome proliferator-activated receptor-a activators. Hypertension. 2005; 46:1086-92.

9. Hoes AW, Jennings CS, Vlachopoulos C, Wood DA, Riccardi G, De Backer G, Drexel H, Zamorano JL, Tokgozoglu L, Chapman MJ, Cooney M-T, Taskinen M-R, Wiklund O, Pedersen TR, Landmesser U, WMM V, Reiner Ž, Catapano AL, Graham I, Group ESD. 2016 ESC/EAS guidelines for the management of dyslipidaemias. Eur Heart J. 2016;37:2999-3058.

10. Sacks FM. After the Fenofibrate Intervention and Event Lowering in Diabetes (FIELD) study: implications for fenofibrate. Am J Cardiol. 2008;102: 34L-40L.

11. Group AS, Ginsberg HN, Elam MB, Lovato LC, Crouse JR 3rd, Leiter LA, Linz P, Friedewald WT, Buse JB, Gerstein HC, Probstfield J, Grimm RH, Ismail-Beigi F, Bigger JT, Goff DC Jr, Cushman WC, Simons-Morton DG, Byington RP. Effects of combination lipid therapy in type 2 diabetes mellitus. N Engl J Med. 2010;362:1563-74.

12. Jun M, Foote C, Lv J, Neal B, Patel A, Nicholls SJ, Grobbee DE, Cass A, Chalmers J, Perkovic V. Effects of fibrates on cardiovascular outcomes: a systematic review and meta-analysis. Lancet. 2010;375:1875-84.

13. Nasu K, Tsuchikane E, Katoh O, Vince DG, Virmani R, Surmely JF, Murata A, Takeda Y, Ito T, Ehara M, Matsubara T, Terashima M, Suzuki T. Accuracy of in vivo coronary plaque morphology assessment: a validation study of in vivo virtual histology compared with in vitro histopathology. J Am Coll Cardiol. 2006;47:2405-12

14. Fanaroff AC, Zakroysky P, Dai D, Wojdyla D, Sherwood MW, Roe MT, Wang TY, Peterson ED, Gurm HS, Cohen MG, Messenger JC, Rao SV. Outcomes of $\mathrm{PCl}$ in relation to procedural characteristics and operator volumes in the United States. J Am Coll Cardiol. 2017;69:2913-24.
15. Lee SW, Hau WK, Kong SL, Chan KK, Chan PH, Lam SC, Tam FC, Wong MK, Chan CW, Lam YM, Tse HF, Chan RH. Virtual histology findings and effects of varying doses of atorvastatin on coronary plaque volume and composition in statin-naive patients: the VENUS study. Circ J. 2012;76:2662-72.

16. Hong MK, Park DW, Lee CW, Lee SW, Kim YH, Kang DH, et al. Effects of statin treatments on coronary plaques assessed by volumetric virtual histology intravascular ultrasound analysis. JACC Cardiovasc Interv. 2009;2:679-88.

17. Koh KK, Han SH, Quon MJ, Ahn JY, Shin EK. Beneficial effects of fenofibrate to improve endothelial dysfunction and raise adiponectin levels in patients with primary hypertriglyceridemia. Diabetes Care. 2005;28:1419-24.

18. Roh E, Ko S-H, Kwon H-S, Kim NH, Kim JH, Kim CS, Song K-H, Won JC, Kim DJ, Choi SH, Lim S, Cha B-Y. Prevalence and management of dyslipidemia in Korea: Korea National Health and Nutrition Examination Survey during 1998 to 2010. Diabetes Metab J. 2013;37:433-49.

19. Kim K-i. Distribution of blood cholesterol profile in untreated Korean population. Korean Circ J. 2015;45:108-9.

20. Shin DI, Baek SH, Her SH, Han SH, Ahn Y, Park KH, Kim DS, Yang TH, Choi DJ, Suh JW, Kwon HM, Lee BK, Gwon HC, Rha SW, Jo SH. The 24-month prognosis of patients with positive or intermediate results in the Intracoronary Ergonovine Provocation Test. JACC Cardiovasc Interv. 2015;8:914-23.

21. Ren J, Grundy SM, Liu J, Wang W, Wang M, Sun J, Liu J, Li Y, Wu Z, Zhao D. Long-term coronary heart disease risk associated with very-low-density lipoprotein cholesterol in Chinese: the results of a 15-year Chinese MultiProvincial Cohort Study (CMCS). Atherosclerosis. 2010;211:327-32.

22. Lim S, Shin H, Song J, Kwak SH, Kang SM, Yoon JW, Choi SH, Cho SI, Park KS, Lee HK, Jang HC, Koh KK. Increasing prevalence of metabolic syndrome in Korea: the Korean National Health and Nutrition Examination Survey for 1998-2007. Diabetes Care. 2011;34:1323-9.

23. Nordestgaard BG, Varbo A. Triglycerides and cardiovascular disease. Lancet. 2014;384:626-35.

24. Group H-TC. Effects of extended-release niacin with laropiprant in high-risk patients. N Engl J Med. 2014;371:203-12.

25. Investigators A-H. Niacin in patients with low HDL cholesterol levels receiving intensive statin therapy. N Engl J Med. 2011;365:2255-67.

26. Birjmohun RS, Hutten BA, Kastelein JJ, Stroes ES. Efficacy and safety of highdensity lipoprotein cholesterol-increasing compounds: a meta-analysis of randomized controlled trials. J Am Coll Cardiol. 2005;45:185-97.

27. Kon Koh K, Yeal Ahn J, Hwan Han S, Kyu Jin D, Sik Kim H, Cheon Lee K, Kyun Shin E, Sakuma I. Effects of fenofibrate on lipoproteins, vasomotor function, and serological markers of inflammation, plaque stabilization, and hemostasis. Atherosclerosis. 2004;174:379-83.

28. Koh KK, Quon MJ, Han SH, Chung WJ, Ahn JY, Seo YH, Choi IS, Shin EK. Additive beneficial effects of fenofibrate combined with atorvastatin in the treatment of combined hyperlipidemia. J Am Coll Cardiol. 2005;45:1649-53.

29. Hahmann HW, Bunte T, Hellwig N, Hau U, Becker D, Dyckmans J, Keller HE, Schieffer HJ. Progression and regression of minor coronary arterial narrowings by quantitative angiography after fenofibrate therapy. Am J Cardiol. 1991;67:957-61.

30. Kooistra T, Verschuren L, de Vries-Van der Weij J, Koenig W, Toet K, Princen $H$, Kleemann R. Fenofibrate reduces atherogenesis in ApoE* 3 Leiden mice: evidence for multiple antiatherogenic effects besides lowering plasma cholesterol. Arterioscler Thromb Vasc Biol. 2006;26:2322-30.

31. Keech A, Simes RJ, Barter P, Best J, Scott R, Taskinen MR, Forder P, Pillai A, Davis T, Glasziou P, Drury P, Kesaniemi YA, Sullivan D, Hunt D, Colman P, d'Emden M, Whiting M, Ehnholm C, Laakso M, investigators Fs. Effects of long-term fenofibrate therapy on cardiovascular events in 9795 people with type 2 diabetes mellitus (the FIELD study): randomised controlled trial. Lancet. 2005;366:1849-61.

32. Glueck CJ, Oakes N, Speirs J, Tracy T, Lang J. Gemfibrozil-lovastatin therapy for primary hyperlipoproteinemias. Am J Cardiol. 1992;70:1-9.

33. Yun KH, Mintz GS, Farhat N, Marso SP, Taglieri N, Verheye S, Foster MC, Margolis MP, Templin B, Xu K, Dressler O, Mehran R, Stone GW, Maehara A. Relation between angiographic lesion severity, vulnerable plaque morphology and future adverse cardiac events (from the Providing Regional Observations to Study Predictors of Events in the Coronary Tree study). Am J Cardiol. 2012;110:471-7.

34. Smith SC Jr, Benjamin EJ, Bonow RO, Braun LT, Creager MA, Franklin BA, Gibbons RJ, Grundy SM, Hiratzka LF, Jones DW, Lloyd-Jones DM, Minissian M, Mosca L, Peterson ED, Sacco RL, Spertus J, Stein JH, Taubert KA. AHA/ACCF secondary prevention and risk reduction therapy for patients with coronary and other atherosclerotic vascular disease: 2011 update: a guideline from the 
American Heart Association and American College of Cardiology Foundation endorsed by the World Heart Federation and the Preventive Cardiovascular Nurses Association. J Am Coll Cardiol. 2011;58:2432-46.

35. Lee CW, Kang SJ, Ahn JM, Song HG, Lee JY, Kim WJ, Park DW, Lee SW, Kim YH, Park SW, Park SJ. Comparison of effects of atorvastatin $(20 \mathrm{mg})$ versus rosuvastatin $(10 \mathrm{mg})$ therapy on mild coronary atherosclerotic plaques (from the ARTMAP trial). Am J Cardiol. 2012;109:1700-4.

36. Li YF, Feng QZ, Gao WQ, Zhang XJ, Huang Y, Chen YD. The difference between Asian and Western in the effect of LDL-C lowering therapy on coronary atherosclerotic plaque: a meta-analysis report. BMC Cardiovasc Disord. 2015;15:6.

\section{Publisher's Note}

Springer Nature remains neutral with regard to jurisdictional claims in published maps and institutional affiliations.

Ready to submit your research? Choose BMC and benefit from:

- fast, convenient online submission

- thorough peer review by experienced researchers in your field

- rapid publication on acceptance

- support for research data, including large and complex data types

- gold Open Access which fosters wider collaboration and increased citations

- maximum visibility for your research: over $100 \mathrm{M}$ website views per year

At BMC, research is always in progress.

Learn more biomedcentral.com/submissions 